\title{
Western Capital in the Russian economy
}

\author{
Gennadij G. Zaitsev / B.F. Uvarov*
}

The inflow of foreign, including German, investment into the Russian economy is quite small. Total foreign investment into Russia at the end of 1995 was estimated by the Ministry of the economy as 6 billion dollars.

This obviously does not correspond with potential Russian needs and the opportunities of the global investment market.

The following reasons have been distinguished for low investment activity in Russia.

A number of factors external to enterprises have constrained the investment process; These include, political instability, the crisis situation in the Russian economy, existing tax systems, an underdeveloped financial system and the common weakness of business infrastructures.

In the opinion of some Western analysts and businessmen, low investment activity is caused by internal corporate reasons such as; unsatisfactory quality of management at the level of the enterprise, including marketing, poor organisational cultures and the inadequacy of a significant proportion of top managers.

Such a conclusion was arrived at, in particular, by the participants of an international conference „Perspectives of the investments into Russia- direct investment and purchasing of actions“ held in New York, March 1996. As an example of the Russian point of view, one of the participants brought the statement of the Director of a Russian paper mill: „I make paper!“. A western partner replied to this, „You should make money!“

Words such as „marketing“, „restructuring“, „increase in efficiency“, „reduction in expenses“ and ,actional price growth“ are avoided by managers as they may distress the Chairmen of the Moscow committee for the protection of shareholder rights.

* Gennadij G. Zaitsev, Human Resource Management Faculty, St Petersburg University of Economics and Finances.

B.F. Uvarov, Human Resource Management Faculty, St Petersburg University of Economics and Finances. 
A number of researchers analysing Russia connect problems of investment with the adequate or inadequate actions of Boards of Directors in the new economic conditions. Statistical material is gradually being accumulated which firstly confirms the interrelationship between international characteristics of enterprises with their success in attracting and using foreign investments, and secondly, which shows that privatised enterprises have most problems concerning „new investments - old regulations“.

So, the results of a survey in 1995 of large enterprises in the St. Petersburg Federal system, showed that in 92-95\% of cases the reason for bankruptcy of enterprises related to the actions of the directors, including those in the field of marketing ... (and in only 5-8\% of cases of bankruptcy is it possible to blame the policy)

This conclusion was confirmed at the above mentioned conference in New York by chiefs of large Russian enterprises. Thus, B. Kasakow, who is the first deputy director of the firm „Norilsky Nickel“ devoted the bulk of his speech to social problems of the firm. Concerning its financial position (the firm produce $90 \%$ of Russian, and $20 \%$ of world nickel), Kasakow said only „It cannot be called good, but it is also not critical“. The Chairman of the Board of the „Bio processor" Group, K. Bendukidse, announced to the conference participants „Russian companies are actually not real companies, only $20 \%$ of them behave on the market, $20 \%$ have absolutely non market behaviour, and $60 \%$ of them are in an intermediate condition between these two poles".

In 1992-95 our research showed that enterprises cannot effectively participate in investment projects unless a number of basic problems are solved:

1. Privatised enterprises are able to adapt to the external environment.

2. Privatised enterprises are able to reach their purposes, which are defined as a consequence of adaptation.

3. To research these purposes, privatised enterprises should possess sufficient internal unity.

4. Internal unity should be maintained by the quality of management, and by the new organisational culture.

The Resolution of these problems first of all rests upon the administrative quality and socio-psychological potential of top management personnel. Personnel of Russian enterprises vary from one to another in terms of:

- degree of adaptation to the sharply changing external environment

- level of readiness to play by new economic rules

- level of aggression in their behaviour on forming markets

In Europe and in the U.S. there exist special centres which estimate the investment potential of firms and their top managers.

In diagnosing managerial quality, Russian enterprises may be viewed as social systems, and decisions made about whether to invest into one or another project. 
Questions to be asked may include: Why invest in an enterprise with non-market organisational potential, with negative socio-psychological characteristics? Is it possible to entrust money into the socio-psychological characteristics of personnel? Is it possible to invest in an enterprise whose top managers possess low authority, insufficient competence and low status qualities? Why invest in such projects where personnel may be the object of manipulation by investors, rendering strong resistance to changes?

The actuality of such diagnosis is explained by significant distinctions in the potential of top managers of Russian enterprises according to the following categories;

aspiration to stabilisation / aspiration to radical innovations

hostile attitude to changes / completely enthusiastic attitude to changes

overall avoidance of risk / acceptance of risk

orientation towards the past / orientation towards the future

Essential distinctions relate to such factors as the organisational culture of Russian enterprises, individual and group behavioural norms, values, interactive processes, management styles, top management qualifications and reaction towards innovation and change.

Not to study these distinctions, or not to react to them, would create a significant risk for investments and credits. This risk can be considerably reduced if the potential investor possesses the appropriate information. Our research has enabled us to develop criteria for express diagnosis of the enterprise, and attention has been concentrated on the following aspects:

\section{Managers}

1. Orientation, comparative predisposition of resolution of internal / external problems

- orientation on the past / future, preparedness to take risks

- behaviour of particular managers, is it conducive to success?

- values, norms and personal objectives of managers

2. Authority

- degrees and levels of assertion of authority on the official hierarchy of enterprises

- ambition and propensity to use authority

3. Personal competence

- ability, qualities

- skill to resolve problems

- style of leadership, based on policy / traditions / inspiration / business / personal charm

- knowledge of the enterprise and its environment 


\section{Opportunity}

- personnel work capacity

- working methods

\section{Climate}

5. Organisation Structure

- attitude towards organisational changes; hostile, neutral, enthusiastic

- readiness to take risks, preferences of top management in risk avoidance or risk taking

- temporal perspectives, does management perceive problems on the basis of past experiences, the present, or with an emphasis on the future?

- activity, are attention and resources concentrated upon internal activity or the external environment?

- behavioural aspects, is the aspiration towards the stabilisation of production efficiency, or growth of output and innovation?

- what stimulates change? crisis, unsatisfactory results over long periods of time, or constant aspiration towards innovation?

- what are viewed as the major factors for success?

6. Distribution of power-distribution between various groups and various cultures

- degree of structural stability of power

- vigilance of power

\section{Competence}

7. Methods of organisational problem solving- reference to latest research, trial and error methods, optimising available and new alternatives

8. Problem solving procedures, divisional or for the whole organisation

9. Managerial processes (formal and informal structures); orientation towards latest data, well known parameters, or new, future, parameters

10. Management information; actual data, or derived through extrapolation, deduced through scanning the external environment.

11. Organisational structure; type of structure, degree of complexity, flexibility and adaptability.

12. Compensation and economic stimulus; management is paid for achieved targets, growth criteria, initiative and creativity,

13. Results orientation; Specific or general, initiative and creativity.

14. Technological facilitation of decision making;

(Computer procedures, rules, models etc.); orientation towards repetitive operations, or towards innovation and change?

The main conclusions are:

Firstly, the quality of management, organisational cultures and potential of Boards of Directors in Russia are quite heterogeneous. 
Secondly, not to take account of this would lead to a serious risk for Western investment and would also contradict the Russian interest. 